\title{
Сравнительный морфологический анализ популяций видов р. Achillea в южной части Красноярского края и Хакасии
}

\section{Comparative morphological analysis of Achillea populations in the southern part of Krasnoyarsk Krai and Khakassia}

\author{
Стоянова Э. Е., Ямских И. Е. \\ Stoyanova E. E., Yamskikh I. E. \\ Сибирский федеральный университет, г.Красноярск, Россия.E-mail: skiforever09@mail.ru, iyamskikh@mail.ru \\ Siberian Federal University, Krasnoyarsk, Russia
}

Peфepam. Изучена внутри- и межпопуляционная изменчивость и проведен анализ сходства популяций двух видов p. Achillea (A. millefolium и A. asiatica), произрастающих в сообществах южной части Красноярского края и Хакасии. Методом главных компонент выделены следующие диагностические признаки: высота общего соцветия, ширина рахиса с крылом, размеры листьев срединой и верховой формаций и количество трубчатых цветков. Четкая дифференциация на виды отмечается только для популяций, характеризующихся минимальными и максимальными значениями данных признаков. Емельяновские популяции, состоящие из крупных особей и произрастающие на границе луговых и лесных сообществ, относятся к виду A. millefolium, а популяции, произрастающие на остепненных лугах, - К A. asiatica. С большей частью изученных популяций тысячелистника возникли трудности при определении видовой принадлежности, видимо связанные с наличием переходных форм гибридогенного происхождения. По совокупности выделенных диагностических признаков данные популяции входят в один кластер с A. asiatica.

Ключевые слова. Кластерный анализ, метод главных компонент, морфологический анализ, Achillea millefolium, Achillea asiatica.

Summary. Intra- and inter-population variability was studied and the similarity of populations of two species of the genus Achillea (A. millefolium and A. asiatica) growing in the communities of the southern part of the Krasnoyarsk territory and Khakassia was analyzed. The principal component analysis identified the following diagnostic features: the height of the common inflorescence, the width of the rachis with the wing, the size of the leaves in the middle and the upper formations and the number of tubular flowers. However, a clear differentiation into species is observed only for populations characterized by minimum and maximum values of these characteristics. Yemelyan populations, consisting of large individuals and growing on the border of meadow and forest communities, belong to the species A. millefolium, and populations, growing on steppe meadows - to A. asiatica. With most of the studied populations of yarrow, there were difficulties species identification, apparently associated with the presence of transitional forms of hybridogenic origin. According to the set of selected diagnostic features, these populations are included in one cluster with A. asiatica.

Key words. Achillea millefolium, Achillea asiatica, cluster analysis, morphological analysis, principal component analysis.

Achillea millefolium s. 1. является самым распространенным видом рода тысячелистник в Сибири, а также полиморфным видом и имеет много форм различного таксономического значения, обычно неясно отграниченных друг от друга (Афанасьев, 1961). Данное растение представляет большой интерес в связи с широким спектром фармакологических свойств (Соколов, 1993). Для комплексного изучения необходим подход, который включает в себя изучение биологии вида на организменном и популяционном уровне (Чудновская, 2013).

В связи с накоплением гербарного материала, показывающего высокую степень внутривидовой изменчивости у видов р. Achillea, возникла необходимость критического пересмотра «видов», которые ранее были выделены из состава A. millefolium, а также ревизии отдельных форм данного полиморфного комплекса. 
Цель работы - сравнительный морфологический анализ популяций видов Achillea asiatica Serg. и Achillea millefolium L., произрастающих в сообществах южной части Красноярского края и Хакасии.

Сбор фактического материала проводился в июле-августе 2017 г. В ходе экспедиционных исследований был собран материал для изучения внутри- и межпопуляционной изменчивости видов и выявления наиболее значимых таксономических признаков. Полученные данные были подвергнуты стандартной статистической обработке (Шмидт, 1984). Изучение сходства популяций и поиск признаков-индикаторов, имеющих диагностическое значение, проведены с помощью кластерного анализа и метода главных компонент в программе «Statistica 10».

Объектами исследований явились 4 популяции Achillea millefolium (Am) и 6 популяций Achillea asiatica (Aa), произрастающие в следующих сообществах: Am1 - березняк разнотравно-осочковый (г. Красноярск, окр. Сибирского федерального университета); Am2 - луг разнотравно-злаковый (окр. аэропорта Емельяново, зона экотона), Am3 -луг крупнотравно-злаковый (Емельяновский район, окр. с. Зеледеево, зона экотона), Am4 - луг разнотравный (Манский район, окр. пос. Манский), Aa1 -суходольный луг злаково-разнотравный (Емельяновский район, окр. д. Дрокино), Аа2 - луг злаково-разнотравный (окр. пос. Манский), Аа3 - луг разнотравно-осочковый (Большеулуйский район, окр. с. Большой Улуй), Аа4 луг разнотравно-злаковый (окр. с. Большой Улуй), Аа5 - остепненный луг разнотравно-злаковый (Ширинский район, окр. пос. Колодезный), Аа6 -обочина лесной дороги (Шушенский район, национальный парк «Шушенский бор», долина р. Таловки).

Согласно литературным данным (Афанасьев, 1961; Шауло, 1997), два исследованных вида тысячелистника отличаются друг от друга по следующим параметрам: общей длине побега, форме и размерам конечных долек листа, степени опушенности стебля, кратности рассечения листьев, форме и цвету оберток. М. Н. Борский (2014) отмечает, что A. millefolium проявляет высокую степень внутривидовой изменчивости. Степанов Н. В. (2016) для разделения видов предлагает обращать внимание на такие признаки, как расстояние между долями листьев, ширину рахиса с крылом, кайму листочков обертки. В результате особи, взятые нами из разных биотопов, могут существенно различаться между собой по значениям многих признаков. На основании анализа данных признаков первоначально нами были выделены популяции тысячелистника. Данные признаки также использовались нами, наряду с другими, для сравнительного морфологического анализа популяций видов.

В ходе исследований выявлено, что большинство вегетативных признаков A. asiatica и A. millefolium имеют высокий и очень высокий уровень изменчивости, согласно шкале С. А. Мамаева (1972). К относительно стабильным признакам с низкой степенью вариабельности относятся: количество листьев, длина долей первого и второго порядка листьев срединной формации, длина трубчатых и язычковых цветков.

Наибольший уровень изменчивости признаков наблюдается для особей популяций Аa3, Aa4 и Aa6, произрастающих соответственно в окрестностях с. Большой Улуй и на обочине лесной дороги в долине р. Таловки. Высокий уровень полиморфизма данных популяций, возможно, связан с тем, что на данных пробных площадях одновременно с A. asiatica произрастают трудно дифференцируемые особи, возможно, относящиеся к A. millefolium, или переходные формы гибридогенного происхождения.

При сравнении среднепопуляционных значений признаков выявлено, что для особей A. millefolium характерны крупные размеры вегетативных органов по сравнению с особями A. asiatica. Например, средняя длина стебля у особей популяции Am3 составляет 78,12 $\pm 2,66$ см, a Aa1 - 32,13 \pm 1,3 см. Ширина рахиса с крылом в популяции Am3 равна $0,34 \pm 0,01$ см, а в Aa1 - 0,24 $\pm 0,01$ см, а расстояние между долями первого порядка листа серединной формации у $\mathrm{Am} 3$ составляет $0,32 \pm 0,02 \mathrm{cm,} \mathrm{a}$ у Aa1 - 0,16 \pm 0,01 см. Также для особей A. asiatica отмечено достоверное снижение размеров листьев срединной и верховой формаций. Наиболее типичными признаками A. millefolium обладают особи емельяновских популяций Am2 и Am3, произрастающие на границе луговых и лесных сообществ. Особи $\mathrm{Am} 1$ и Am4 достоверно отличаются от большинства популяций A. asiatica только по длине стебля и размерам листа срединой формации.

При изучении сопряженной изменчивости морфометрических признаков тысячелистника использовался метод главных компонент. Выявлено, что первые три фактора (компоненты) являются значимыми. Их собственные значения превышают 1, а суммарный вклад в общую дисперсию равен 
93,27 \%. Анализ значений весовых коэффициентов каждого признака при первой компоненте позволяет предположить, что наиболее тесно с ней связаны отрицательной связью параметры осевых органов, размеры листьев и их долей, количество и диаметр корзинок. Вторая компонента имеет сильную отрицательную связь с количеством и длиной трубчатых цветков, длиной язычковых цветков. Третья компонента наиболее связана с количеством листьев. В плоскости первой и второй главных компонент популяции A. asiatica образуют более плотную группу, тогда как популяции A. millefolium не формируют единого комплекса (рис. 1). Емельяновские популяции Am2 и Am3 близки друг другу по признакам вегетативных органов, но расходятся в плоскости второй компоненты (Am2, в отличие от Am3, характеризуется мелкими трубчатыми и язычковыми цветками). Красноярская популяция Am1, произрастающая в березняке, располагается в группе популяций A. asiatica, отличаясь от последних длиной стебля.

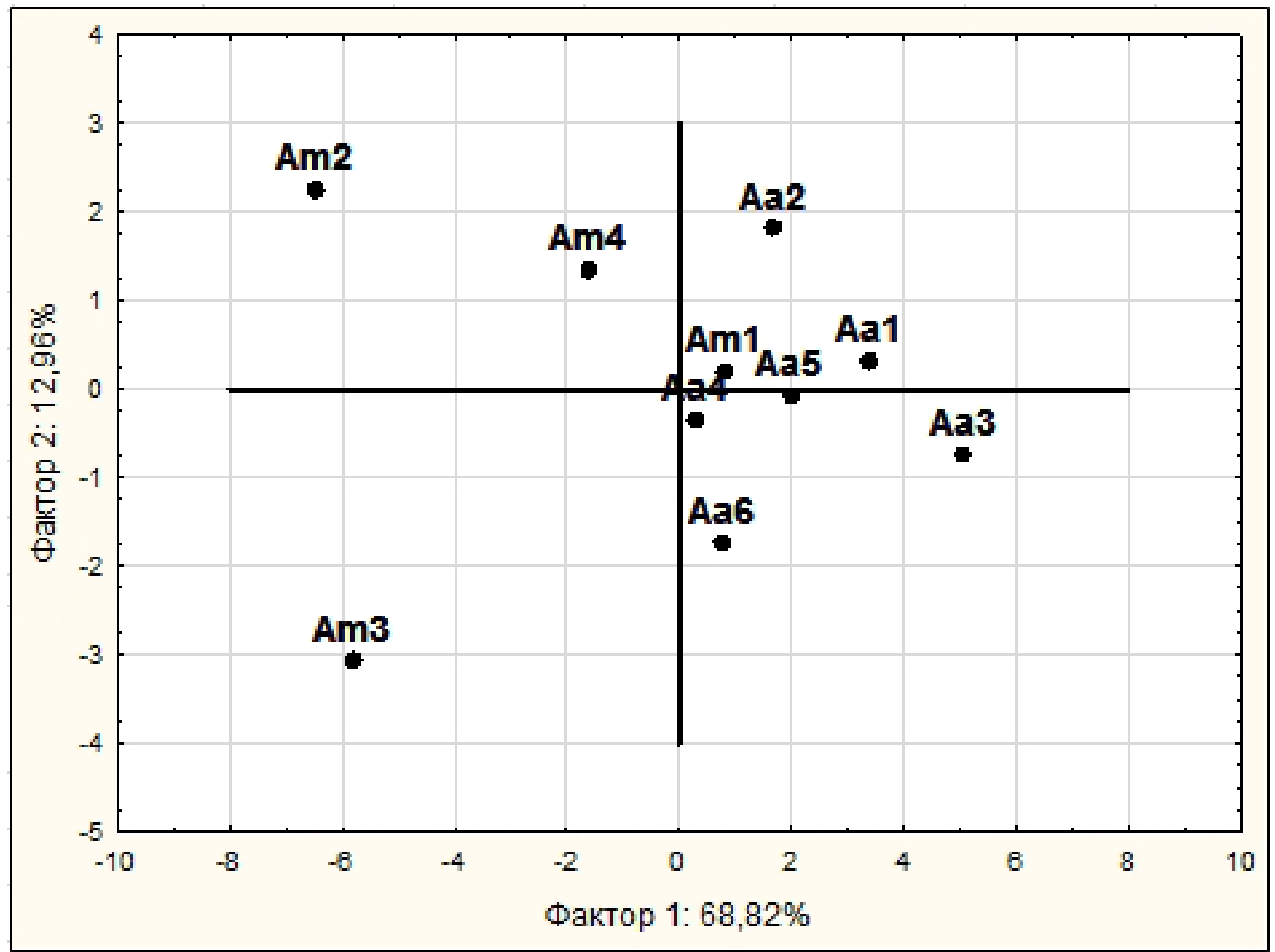

Рис. 1. Ординация популяций A. asiatica и A. millefolium в плоскости главных компонент.

Для оценки морфологического сходства изучаемых популяций использовался кластерный анализ (рис. 2). В обработке применялся метод Уорда. В качестве меры сходства использовалось Евклидово расстояние. В анализе использовались признаки, имеющие максимальные веса при главных компонентах. Выявлено четкое разделение популяций тысячелистника на два кластера: первый образуют две емельяновские популяции $\mathrm{Am} 2$ и $\mathrm{Am} 3$, характеризующиеся крупными размерами вегетативных органов. Второй кластер можно разделить на 3 субкластера. Наибольшее сходство отмечается между Аа1 и Aa3, произрастающими на остепненных лугах и имеющими наиболее типичные признаки $A$. asiatica. Большеулуйские популяции Аa4, Aa5 и ширинская Аа6 также образуют единую группу, морфологически близкую к манским Aa2, Am4 и красноярской Am1. Следовательно, популяции Am4 и Am1, ранее относимые нами к виду A. millefolium, либо относятся к виду A. asiatica, либо представляют собой смешанную группу из двух видов р. Achillea. 


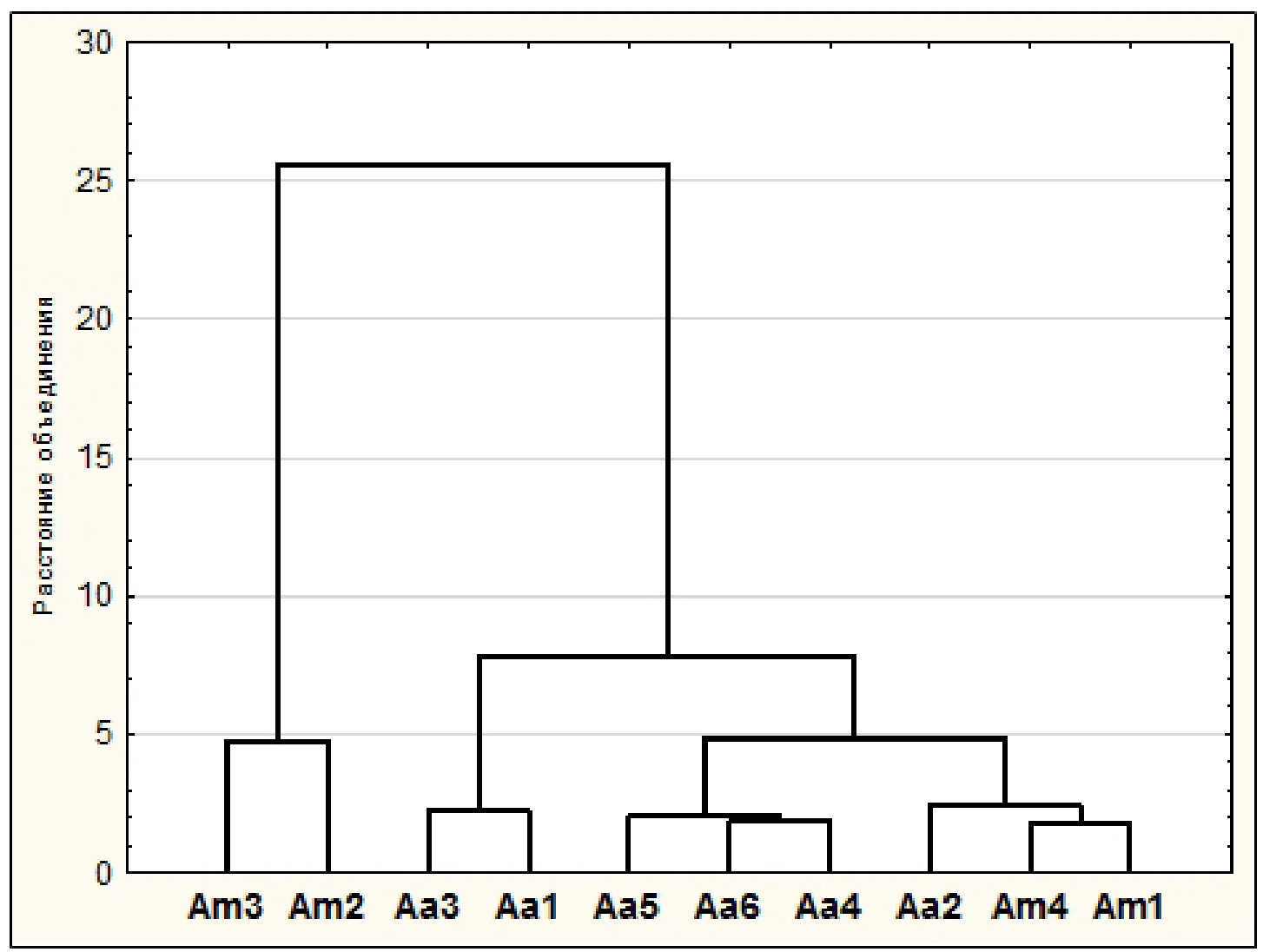

Рис. 2. Дендрограмма сходства популяций A. asiatica и A. millefolium по морфологическим признакам.

Таким образом, установлено, что четкая дифференциация двух видов тысячелистника возможна для популяций, имеющих крайние значения вегетативных признаков, таких как высота общего соцветия, ширина рахиса с крылом, показатели листьев срединой и верховой формаций и количество трубчатых цветков. Емельяновские популяции, состоящие из крупных особей и произрастающие на границе луговых и лесных сообществ, относятся к виду A. millefolium, а популяции, произрастающие на остепненных лугах, - к A. asiatica. С большей частью изученных популяций тысячелистника возникли трудности при определении видовой принадлежности, видимо связанные с наличием переходных форм гибридогенного происхождения. По совокупности выделенных диагностических признаков данные популяции входят в один кластер с A. asiatica. В дальнейшем будут продолжены исследования по поиску признаков, имеющих таксономическое значение, в том числе и генетических маркеров.

\section{ЛИТЕРАТУРА}

Aфанасьев К. C. Род Achillea L. - тысячелистник // Флора СССР. - М.-Л.: Изд-во АН СССР, 1961. - Т. 26. - С. $78-86$.

Борский М. Н. Морфологический полиморфизм Achillea millefolium S.L. в Самарской области // Вестник МГОУ. Серия «Естественные науки». - Москва: Изд-во МГОУ, 2014. - № 1. - С. $29-42$.

Соколов П. Д. Растительные ресурсы СССР. Цветковые растения, их химический состав, использование: Семейство Asteraceae. - СПб.: Наука, 1993. - 349 с.

Cтепанов Н. B. Разнообразие тысячелистников (род Achillea L. - Asteraceae) в приенисейских Саянах // Вестник КрасГАУ. - Красноярск: Изд-во КрасГАУ, 2016. - № 6. - С. 31-38.

Мамаев С. А. Формы внутривидовой изменчивости древесных растений. - М.: Наука, 1973. -284 с.

Чудновская Г. В. Тысячелистник азиатский (Achillea asiatica Serg.) в Восточном Забайкалье // Известия Оренбургского гос. аграр. ун-та. - Оренбург: ОГАУ, 2013. - С. 28-31.

Шмидт В. М. Математические методы в ботанике. - Ленинград : ЛГУ, 1984. - 288 с.

Шауло Д. Н. Род Achillea L. - тысячелистник // Флора Сибири. - Новосибирск: Наука, 1997. - Т. 13. - С. 65-70. 